\title{
A Study of the Effect of Building Designs on Climate Change: Mitigation and Adaption
}

\author{
Repaul Kanji, Sonam Sahu, and Robin Agarwal
}

\begin{abstract}
Urbanization and development are the inevitable consequences of economic growth. With urbanization, various issues of climate change are cropping up. Urban Heat Island (UHI) is a significant phenomenon to manifest the changes in climate of a region. The present research attempts to establish the presence of this phenomenon in Roorkee, India on one hand. And, to study change in architectural styles of the buildings in the course of time as the possible reasons of these climatic differences on the other hand. Finally, the research concludes with recommendations and suggestion to mitigate and adapt to climate changes through the implementation of an indigenously designed algorithm.
\end{abstract}

Index Terms-Uhi, surface transformation, land surface temperature, minimum u-value algorithm.

\section{INTRODUCTION}

Urbanization has lead to transformation of natural surfaces to urban land. Construction of buildings and infrastructure has made undue unavoidable changes in land surface properties. One important property is the land surface temperature (LST). LST is responsible for the change in air temperature of a region [1]. Anthropogenic activities like use of vehicles and air conditioners, and emission of gases is also responsible for the same. But urban development plays a major role. The type of building material used and the percentage of natural land transformed to urban land are solely responsible for the change in land surface properties. This further result in change of local weather conditions and eventually leads to climate change. The construction of buildings, roads and other impervious surfaces leads to increase of temperature of that region as compared to the surrounding rural area. This phenomenon is known as Urban Heat Island (UHI) [2]. UHI is a significant manifestation of climate change. The present study aims to investigate the presence of UHI in Roorkee, India. 268 meters from mean sea level, Roorkee has an extreme and erratic continental climate. The paper also studies the architectural and construction styles of the various buildings in the study area to empathize the causes of UHI.

Manuscript received January 20, 2014; revised March 23, 2014.

The authors are with the the Indian Institute of Technology Roorkee, Roorkee, 247667 India (e-mail: repaul23@gmail.com, ar.snmsahu@gmail.com,robinagarwa199@gmail.com).

\section{Methodology}

\section{A. Phase I}

Inspired by the work in some UHI studies [3], the first phase of the study is to investigate the existence of UHI in Roorkee. For this, the air temperature of Roorkee needs to be compared with a rural area. The selected rural area is Dhanauri, 13 kilometres away from Roorkee. Specific days of summer and spring season of the year 2013 have been used for the comparison. Hourly data for the time stretch of $16^{\text {th }}-$ $25^{\text {th }}$ April, 2013 and $20^{\text {th }}-29^{\text {th }}$ May, 2013 has been archived from the Meteorological stations for the analysis of UHI. Analyzing nine days, each of spring and summer season, when the climate of Roorkee is in extremes, provided the basis for the proper determination of UHI in the campus.

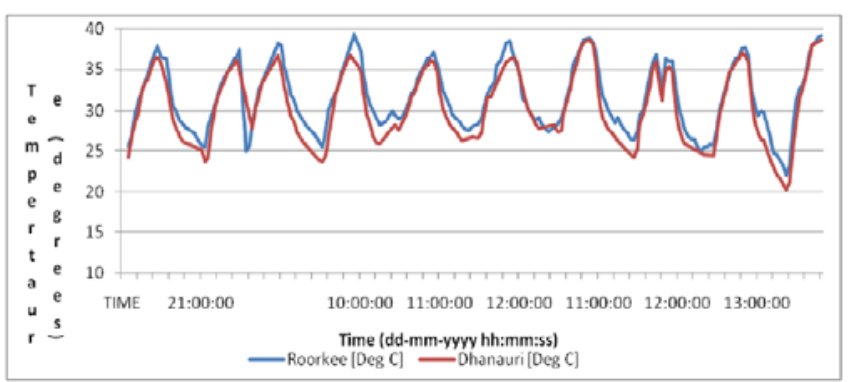

Fig. 1. Graph showing temporal variation of air temperature in summer season in urban and rural sites.

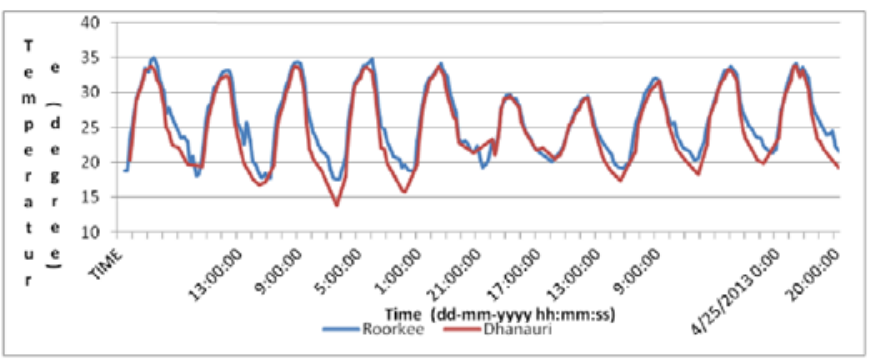

Fig. 2. Graph showing temporal variation of air temperature in spring season in urban and rural sites.

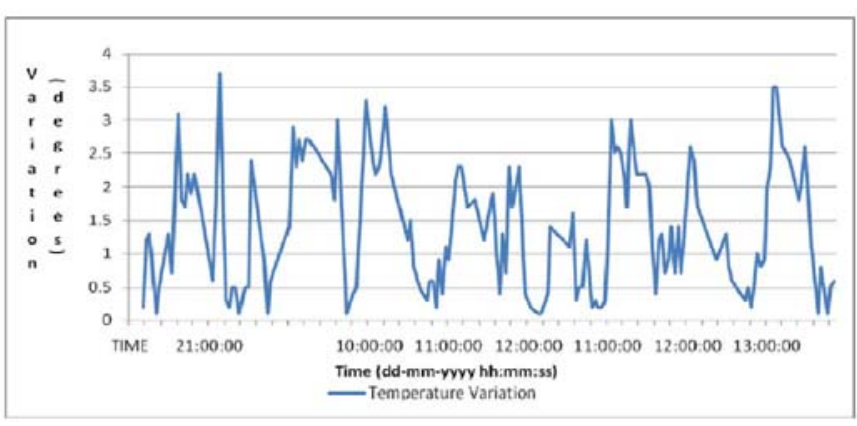

Fig. 3. Temperature variation $\left(t_{u-R}\right)$ in summer season. 


\section{B. Results of Phase 1}

The graphs above (Fig. 1 and Fig. 2) are showing the weather profile of the two selected stations Roorkee and Dhanauri (urban and rural respectively). Fig. 3 and Fig. 4 show the temperature variation $\left(T_{U-R}\right)$ in summer and spring seasons. There is at most around 3.5 degrees variation in the temperature from the nearby rural area in the summer season ranging from 0.1 to 3.5 degrees, and about 3.8 degrees in the springs ranging from 0.2 to 3.8 degrees.

TABLE I: RESULTS OF CAMPUS DOCUMENTATION

\begin{tabular}{|c|c|c|c|c|c|c|c|c|c|c|}
\hline Sr. no. & $\begin{array}{l}\text { Site } \\
\text { description }\end{array}$ & Structure & Surroundings & $\begin{array}{l}\text { Tree } \\
\text { cover }\end{array}$ & Pollution & $\begin{array}{l}\text { Building } \\
\text { Height }\end{array}$ & $\begin{array}{l}\text { Distance from } \\
\text { nearest } \\
\text { building } \\
\text { (approx) } \\
\end{array}$ & $\begin{array}{l}\text { Roughness } \\
\text { class }^{1}\end{array}$ & $\begin{array}{l}\text { \% open/ } \\
\text { built }^{2}\end{array}$ & Category \\
\hline $\begin{array}{l}\text { Site } 1 \\
\text { (Hoste) }\end{array}$ & residential & $\mathrm{RCC}$ & $\begin{array}{l}\text { commercial/ } \\
\text { residential }\end{array}$ & Medium & medium & $9 \mathrm{mtrs}$ & $8 \mathrm{mtrs}$ & 0.5 & $30-70$ & $\mathrm{U}$ \\
\hline $\begin{array}{l}\text { Site } 2 \\
\text { (Lecture } \\
\text { Comple) } \\
\end{array}$ & educational & $\mathrm{RCC}$ & $\begin{array}{l}\text { public/ } \\
\text { educational }\end{array}$ & Low & high & $20 \mathrm{mtrs}$ & $12 \mathrm{mtrs}$ & 1 & $20-80$ & U \\
\hline $\begin{array}{l}\text { Site } 3 \\
\text { (Manageme } \\
\text { nt Building) }\end{array}$ & educational & $\mathrm{RCC}$ & educational & Low & high & $8 \mathrm{mtrs}$ & $12 \mathrm{mtrs}$ & 1 & $20-80$ & U \\
\hline $\begin{array}{l}\text { Site } 4 \\
\text { (Hill View } \\
\text { apartments) }\end{array}$ & residential & $\mathrm{RCC}$ & $\begin{array}{l}\text { residential/ } \\
\text { educational }\end{array}$ & Low & high & $24 \mathrm{mtrs}$ & 9 mtrs & 1 & $20-80$ & $\mathrm{U}$ \\
\hline $\begin{array}{l}\text { Site } 5 \\
\text { (Shivalik } \\
\text { Apartments) }\end{array}$ & residential & $\mathrm{RCC}$ & $\begin{array}{l}\text { residential/ } \\
\text { educational }\end{array}$ & Low & high & $21 \mathrm{mtrs}$ & $6 \mathrm{mtrs}$ & 1 & $20-80$ & U \\
\hline $\begin{array}{l}\text { Site } 6 \\
\text { (Department) }\end{array}$ & educational & $\mathrm{RCC}$ & educational & Medium & medium & $10 \mathrm{mtrs}$ & $25 \mathrm{mtrs}$ & 0.5 & $40-60$ & $\mathrm{~S}$ \\
\hline $\begin{array}{l}\text { Site } 7 \\
\text { (Nescafe) }\end{array}$ & public & $\mathrm{RCC}$ & $\begin{array}{l}\text { commercial/ } \\
\text { educational }\end{array}$ & Medium & high & $2.5 \mathrm{mtrs}$ & $8 \mathrm{mtrs}$ & 0.25 & $50-50$ & $\mathrm{~S}$ \\
\hline $\begin{array}{l}\text { Site } 8 \\
\text { (Residence) }\end{array}$ & residential & $\begin{array}{l}\text { brick } \\
\text { masonry }\end{array}$ & residential & High & low & $3 \mathrm{mtrs}$ & $12 \mathrm{mtrs}$ & 0.25 & $40-60$ & S \\
\hline $\begin{array}{l}\text { Site } 9 \\
\text { (Residence) }\end{array}$ & residential & $\begin{array}{l}\text { brick } \\
\text { masonry }\end{array}$ & residential & High & low & $3 \mathrm{mtrs}$ & $22 \mathrm{mtrs}$ & 0.25 & $60-40$ & $\mathrm{~S}$ \\
\hline $\begin{array}{l}\text { Site 10 } \\
\text { (Residence) }\end{array}$ & residential & $\begin{array}{l}\text { brick } \\
\text { masonry }\end{array}$ & educational & High & medium & $6 \mathrm{mtrs}$ & $12 \mathrm{mtrs}$ & 0.25 & $60-40$ & S \\
\hline $\begin{array}{l}\text { Site 11 } \\
\text { (Main } \\
\text { Building, } \\
\text { Academic } \\
\text { Institute) } \\
\end{array}$ & $\begin{array}{l}\text { administrati } \\
\text { ve building }\end{array}$ & $\begin{array}{l}\text { brick } \\
\text { masonry }\end{array}$ & $\begin{array}{l}\text { public/ } \\
\text { educational }\end{array}$ & Medium & low & $8 \mathrm{mtrs}$ & $15 \mathrm{mtrs}$ & 0.5 & $40-60$ & S \\
\hline $\begin{array}{l}\text { Site } 12 \\
\text { (Workers } \\
\text { residences) }\end{array}$ & residential & $\begin{array}{l}\text { sun } \\
\text { dried } \\
\text { bricks }\end{array}$ & residential & Medium & low & $2.5 \mathrm{mtrs}$ & $3 \mathrm{mtrs}$ & 0.25 & $40-60$ & $\mathrm{R}$ \\
\hline
\end{tabular}

Roughness class allotted according to Classification of Effective Terrain Roughness (Revised 2000), Source: Davenport et al., (2000) [4] in Oke (2006)[5], Average percentage of ground covered with impermeable material to permeable material, U-Urban, S- Suburban, R-Rural

\section{Phase 2}

The second phase is the documentation of buildings belonging to different architectural and construction styles in the study area. Surveys were conducted to cover almost all the varied typologies, based on certain parameters which generally contribute to UHI. Parameters like building material, percentage built/open space, tree-cover, pollution, building geometry were noted. The outcomes are presented in Table I in the Appendix.

\section{Results of Phase 2}

The sites 2, 3, 4 and 5 respectively are recently built structures and which are profusely modern. These are designed not according to the existing climate, but for artificial heating and cooling. The structures witness $80 \%$ transformed surfaces. The construction of asphalt and concrete roads, extensive use of building materials like concrete and glass on building skin is responsible for increasing the temperature at micro level. The absence of tree cover further ads to the issues of heat gain as there is no evapo-transpiration allowed. Absence of permeable surface hampers the humidity level of the area, allows more solar radiation to get absorbed, and reduces the expected precipitation. On the other hand there are other sites which show highly distinguishable lineament. Site 6, 7, 8, 9, 10 and 11 are suburban. Out of these, the Site 6 and 7 are built up of $\mathrm{RCC}$, but the percentage of human intervention in changing the character of land is appreciably less. The softscape is mostly natural and undisturbed. The play of nature has not been interfered with; it has been kept safe and untouched. All what has been done is the addition of few gathering spaces for utilization and leisure. So there has been least intervention in the natural setup. Next are the sites 8, 9 and 10. These are typical examples of vernacular in Roorkee showing 
assemblage of the brilliantly designed arrangement of the built and open spaces. These buildings have brick masonry structure and slab made up of layers of tiles plastered with lime mortar. This thoughtful system of planning and design holds the essential weather factors under assurance, being designed for the local climate; no artificial cooling required. The other location is the site 11 is the main building of an educational institute in Roorkee. The structure made up of brick masonry holds a magnificent look and does not need any high order modern material range. With a noticeable part belonging to green spaces the structure has very little harm to make to the climate of the region even though it has a huge amount of ground coverage. The thick brick walls and the slab made up of reinforced brickwork are good for high insulation and low heat gain are responsible for less energy consumption for cooling the interiors. Site 12 is a residential area belonging to the lower income group. The buildings are made up of sun dried bricks. The space is categorized as rural [4], [5] because of the material used for construction and the untouched surroundings.

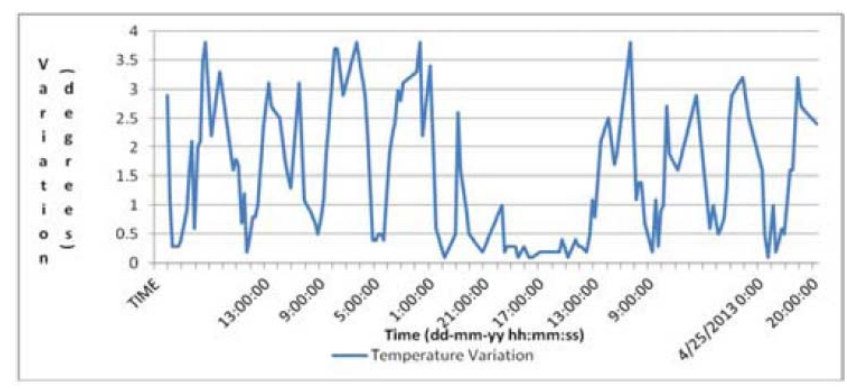

Fig. 4. Temperature variation $\left(T_{U-R}\right)$ in spring season.

\section{CONCLUSION}

While at this, it was perceived that the trend is to gradually move towards modern architectural style. So step should be taken not to stop the progress but to ensure the steps are taken carefully. Hence, the research work suggests an algorithm to select appropriate building materials and components with the lowest U-value or thermal conductivity value. Based on ASHRAE Handbook of Fundamentals [6] and Scottish Governments resource document [7], an inventory can be created of the design $U$ values or thermal conductivities of all the probable and commonly used materials and styles. The algorithm suggests a connected graph, G, to be constructed from a source vertex, say A. From A, edges would link to vertices which are probable options of construction types, with each edge weighing the $U$ value of the material in the vertex it leads to. In turn, every vertex should be connected to every other vertex finally leading to convergent vertex, say B, thus creating a connected, weighted graph of probable options of material or building style. Finally, the following algorithm is run on the graph, G.

$$
\begin{gathered}
\operatorname{MinU}(\mathrm{G}, \text { uvalue, } \mathrm{A}) \\
\text { \{for (each u belongs to } \mathrm{V}) \\
\{ \\
\text { cuvalue }[\mathrm{u}]=\text { infinity } \\
\text { color }[\mathrm{u}]=\text { white }
\end{gathered}
$$

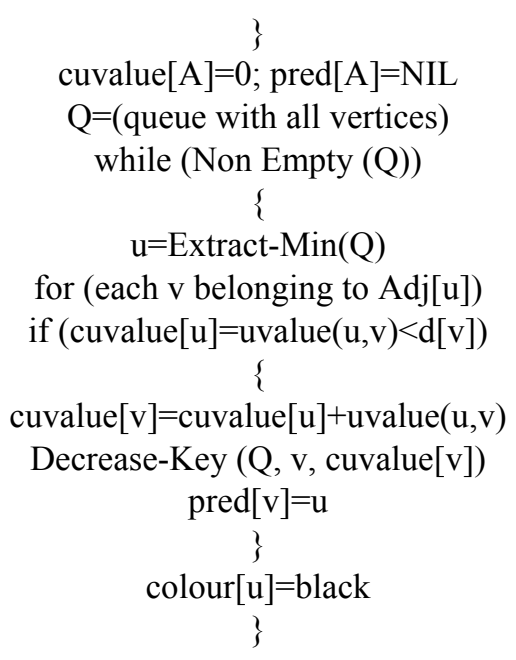

The result optimizes the possibility with the least design $U$ value or thermal conductivity whichever is fed in uvalue[]; cuvalue gives the total calculated uvalue for the specific graph G. The graph is implemented using priority queue and hence typical queue operations can be found. Thus, an optimal algorithm is ready to be implemented to help designers adapt and in a way mitigate the obvious climate changes.

In this context the important strategies that can be listed to ensure the least impact on the climate can be:

1) Innovation in technology and construction process and minimum use of materials with undesirable thermal properties

2) Identifying materials with low carbon footprints and improved thermal properties

3) Using indigenous materials, and manpower instead of heavy machinery

4) Designing and planning for local weather conditions using passive solar design features instead of creating artificial indoor climate and using HVAC.

5) Reducing anthropogenic activities and artificial surface transformation to minimum.

With these schemes, understanding of vernacular technologies and knowledge of material science, it can be possible to build an integrated and successful environment conscious design for the city which will portray its connectivity to the locale, ties with the history $\&$ culture and be a solution for the climatic changes to come in the near future.

\section{REFERENCES}

[1] L. Sberg, The urban climate, Academic Press, New York, 1981.

[2] J. A. Voogt and T. R. Oke, "Thermal remote sensing of urban areas," Remote Sensing of Environment, vol. 86. pp. 370- 384, 2003.

[3] W. N. Hien and S. K. Jusuf, "Geographical information system (GIS) based urban heat islan studi in NUS campus," in Proc. $24^{\text {th }}$ Conference on Passive and Low Energy Architecture, 2007.

[4] Davenport, Classification of Effective Terrain Roughness, 2000.

[5] Oke, "Initial Guidance to Obtain Representative Meteorological Observations at Urban Sites," World Meteorological Organization : Instruments and Observing Methods Report, 2006.

[6] Handbook of Fundamentals, ASHRAE, 1997.

[7] Technical Handbook, Scotland Government, Table 6.A - Tables of U Values and Thermal Conductivity, 2007. 


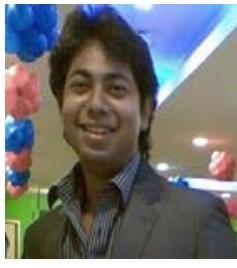

Repaul Kanji is a computer science engineer who is pursuing his research work at the Indian Institute of Technology Roorkee.

After considering a career in the field of information technology, he now uses his erstwhile knowledge of computer science in suggesting solutions and ways to mitigate disasters and manage it.

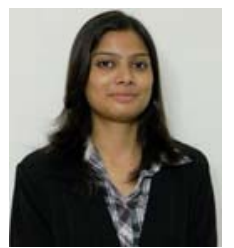

Sonam Sahu is an accomplished architect. She received her master's at the Indian Institute of Technology Roorkee.

Being an architect, she has immense intereset in climatology and sustainable development. She currently is working on fields as diverse as UHI and proposal of cybernetic solutions for the same.

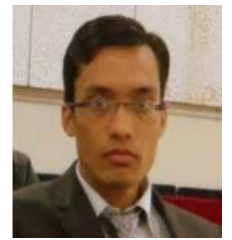

Robin Agarwal is a computer science engineer, who is doing his masters in technology in the subject of disaster mitigation and management at Indian Institute of Technology Roorkee.

In spite of being an engineer, he is pursuing his research works in the field of climate change using several computer aids like GIS. 